ORIGINAL ARTICLE

\title{
Access block causes emergency department overcrowding and ambulance diversion in Perth, Western Australia
}

\author{
D M Fatovich, Y Nagree, P Sprivulis
}

Emerg Med J 2005;22:351-354. doi: 10.1136/emj.2004.018002

See end of article for authors' affiliations ......................

Correspondence to: Dr D M Fatovich,

Department of Emergency Medicine, Royal Perth Hospital, Box X2213 GPO, Perth WA 6847, Australia; daniel.fatovich@íhealth. wa.gov.au

Accepted 14 October 2004

\begin{abstract}
Objective: Access block refers to the situation where patients in the emergency department (ED) requiring inpatient care are unable to gain access to appropriate hospital beds within a reasonable time frame. We systematically evaluated the relationship between access block, ED overcrowding, ambulance diversion, and ED activity.

Methods: This was a retrospective analysis of data from the Emergency Department Information System for the three major central metropolitan EDs in Perth, Western Australia, for the calendar years 2001-2. Bivariate analyses were performed in order to study the relationship between a range of emergency department workload variables, including access block ( $>8$ hour total ED stay for admitted patients), ambulance diversion, ED overcrowding, and ED waiting times.

Results: We studied 259580 ED attendances. Total diversion hours increased $74 \%$ from 3.39 hours/day in 2001 to 5.90 hours/day in 2002. ED overcrowding ( $r=0.96$; $95 \%$ confidence interval (Cl) 0.91 to $0.98)$, ambulance diversion ( $r=0.75 ; 95 \% \mathrm{Cl} 0.49$ to 0.88$)$, and $\mathrm{ED}$ waiting times for care $(r=0.83 ; 95 \%$ $\mathrm{Cl} 0.65$ to 0.93 ) were strongly correlated with high levels of ED occupancy by access blocked patients. Total attendances, admissions, discharges, and low acuity patient attendances were not associated with ambulance diversion.

Conclusion: Reducing access block should be the highest priority in allocating resources to reduce ED overcrowding. This would result in reduced overcrowding, reduced ambulance diversion, and improved ED waiting times. Improving hospital inpatient flow, which would directly reduce access block, is most likely to achieve this.
\end{abstract}

\section{METHODS}

Perth's population of 1.4 million is served by public EDs at four large central metropolitan hospitals (one exclusively paediatric), three smaller outer metropolitan hospitals, and two privately administered public hospitals. In addition, there is one private hospital ED. The capacity of the metropolitan public hospital system to accept ambulances is largely dependent upon the ability of the three main central tertiary hospitals to receive the majority of the ambulance presentations (this was $82 \%$ during the study period).

A retrospective analysis of data from EDIS and the Open Patient Administration System (TOPAS) for calendar years 2001 and 2002 was undertaken. EDIS (version 9) is software provide by Hospital Administration Software Solutions and is used in the public metropolitan EDs in Perth. TOPAS is the inpatient administration system used in all public metropolitan hospitals in Perth.

Bivariate and multivariate analyses were performed to illustrate the relationship between a range of variables likely to be correlated with ED overcrowding, access to emergency care, and ambulance diversion at the three main central tertiary hospitals (Fremantle Hospital, Royal Perth Hospital, and Sir Charles Gairdner Hospital). Each episode of ambulance diversion was recorded on a spreadsheet by the ambulance service at the time it occurred. Table 1 lists the definitions of the variables used for analysis. Analysis was conducted using SPSS (version 11.5; SPSS Inc, Chicago, IL, USA).

\section{RESULTS}

Total ED attendances to the three tertiary hospitals remained stable between 2001 (129 011) and 2002 (130 569). Total

Abbreviations: ED, emergency department; EDIS, Emergency Department Information System; TOPAS, the Open Patient Administration System 
Table 1 Definitions of terms and variables examined

\begin{tabular}{|c|c|}
\hline Total ED overcrowding & $\begin{array}{l}\text { Overcrowding refers to the situation where ED function is impeded, primarily because the number of patients waiting to be seen, } \\
\text { undergoing assessment and treatment, or waiting for departure exceeds the physical or staffing capacity of the ED.' This includes } \\
\text { patients in cubicles, corridors, and waiting rooms }\end{array}$ \\
\hline Access block & An admitted patient who spends more than 8 hours in the ED' \\
\hline Admission & A patient who underwent the formal electronic hospital admission process \\
\hline Low acuity patient & A patient with a problem who, if seen by a general practitioner, would not have presented to an ED ${ }^{16}$ \\
\hline ED capacity & The number of ED treatment areas, excluding observation wards and corridor spaces \\
\hline Total ED occupancy & Proportion of available cubicle hours per month occupied by patients \\
\hline Access block ED occupancy & Proportion of available cubicle hours per month occupied by access blocked patients \\
\hline Australasian triage score & $\begin{array}{l}\text { The ATS is a 1-5 urgency rating given to all patients presenting to the ED. The Australasian College for Emergency Medicine } \\
\text { (ACEM) defines recommended waiting times for each category. ATS } 1 \text { patients have life threatening critical illness that should be } \\
\text { seen by a doctor immediately, whereas ATS } 5 \text { patients are non-urgent patients who can wait up to } 2 \text { hours for medical attention }\end{array}$ \\
\hline Patients seen within threshold & $\begin{array}{l}\text { The percentage of patients who were seen within their recommended time as defined by the ACEM. This is a good measure of ED } \\
\text { performance; a poorly performing ED will be unable to see patients in a timely manner }\end{array}$ \\
\hline ED performance & $\begin{array}{l}\text { The performance of an ED is regarded to be how many patients were seen within their recommended waiting time. A department } \\
\text { is high performing if it sees most of its patients within recommended times, while a poorly performing department has prolonged } \\
\text { waiting times. }\end{array}$ \\
\hline Total diversion time & The total number of minutes the hospitals were on ambulance diversion \\
\hline Triple diversion requests & $\begin{array}{l}\text { The number of times all three central hospitals requested ambulance diversion at the same time. When this occurs, all diversion } \\
\text { requests are cancelled, and ambulances are directed to the nearest hospital or at the discretion of the ambulance shift co- } \\
\text { ordinator. }\end{array}$ \\
\hline Sea surface temperature & $\begin{array}{l}\text { Average monthly sea surface temperature adjacent to Perth as reported by the Commonwealth Scientific and Industrial Research } \\
\text { Organisation }\end{array}$ \\
\hline
\end{tabular}

admissions (mean 42\%) increased slightly, from 54678 in 2001 to 55481 in 2002 .

Total ambulance diversion hours increased $74 \%$ from 3.39 hours/day in 2001 to 5.90 hours/day in 2002 (fig 1). Triple diversion requests (when all three hospitals request ambulance diversion) grew from virtually non-existent in the first half of 2001 to every third day in 2002.

Total ED occupancy, an index of emergency department overcrowding, was shown to have an almost linear correlation with access block ED occupancy ( $\mathrm{r}=0.96,95 \%$ CI 0.91 to $0.98, \mathrm{p}<0.001$; table 2 ). There was also a significant correlation with admissions and sea surface temperature. Given the dependency of total ED occupancy upon access block ED occupancy, access block ED occupancy was used in preference to total ED occupancy to assess the relationship between ED occupancy, ambulance diversion, and waiting time compliance.

Bivariate analysis indicated that access block ED occupancy has a strong positive correlation with ambulance diversion $(\mathrm{r}=0.75,95 \%$ CI 0.49 to $0.88, \mathrm{p}<0.001$; table 2$)$. Fig 2 illustrates the correlation between the rise in access block ED occupancy and the total number of ambulance diversion hours between 2001 and 2002. Between 2001 and 2002, the proportion of access blocked patients increased from $11 \%$ to $16 \%(45 \%$ increase, $\mathrm{p}<0.001)$. Sea surface temperature was also shown to have a correlation with ambulance diversion. Total attendances, low acuity patient attendances, discharges,

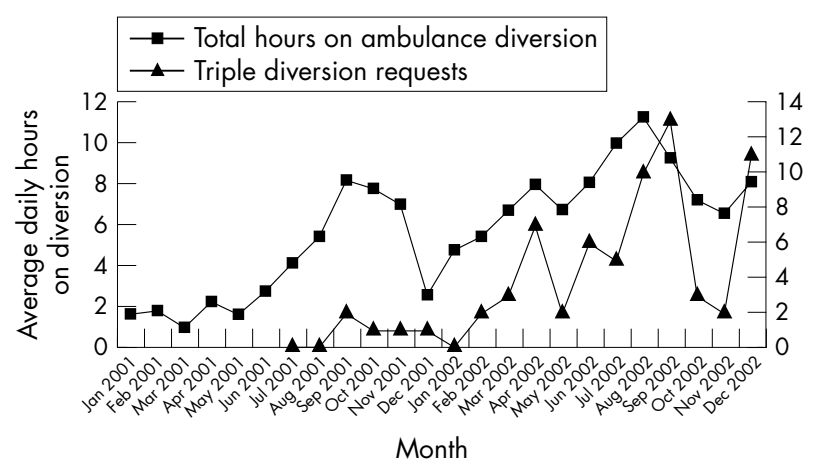

Figure 1 Total ambulance diversion time and triple diversion requests. and admissions were not correlated with ambulance diversion (table 2).

Compliance with recommended waiting time thresholds for care deteriorated from 65\% in January 2001 to $50 \%$ in December 2002 (15\% decrease, $p<0.001$; fig 3). Access block ED occupancy was highly correlated with deterioration in compliance with waiting time thresholds $(\mathrm{r}=0.83,95 \% \mathrm{CI}$ 0.65 to $0.93, p \leqslant 0.001$; table 4$)$. Admissions and total attendances were also shown to have a correlation with waiting time compliance. Sea surface temperature may be weakly correlated with waiting time compliance; however, low acuity patient attendances and discharges were not correlated with waiting time compliance.

The use of stepwise regression to develop models for total ED occupancy, ambulance diversion, or waiting time compliance failed to identify a model including any additional variable independent of access block ED occupancy. All other variables tested in the model are those stated in table 2 .

\section{DISCUSSION}

Our study clearly demonstrates that ambulance diversion and poor ED performance are related to poor inpatient flow. This manifests as the presence of admitted patients in the EDthat is, access block. Despite little change in ED attendances during the study period, we have demonstrated an almost linear relationship between access block ED occupancy and total ED occupancy. Similarly, there was a strong relationship between access block ED occupancy and both ambulance diversion and prolonged ED waiting times.

A winter-spring exacerbation of access block ED occupancy associated with increased ED admissions was identified; however, our attempts at stepwise regression indicated that access block ED occupancy may be used as a single variable to predict the risk of ED overcrowding, ambulance diversion, and prolonged ED waiting times in metropolitan Perth central EDs, regardless of time of year or ED admissions.

Our results concur with other international reports that have found that the presence of inpatients in the ED is the primary reason for ED overcrowding. Schull also found that admitted patients contribute disproportionately to ambulance diversion. ${ }^{8}$ Ambulance diversion has gradually become standard operating procedure in many cities. ${ }^{9}$ Trzeciak also reports that the main cause of ED overcrowding is inadequate inpatient capacity. ${ }^{10}$ Thus, this capacity crisis is now an important public health issue. ${ }^{10-12}$ Furthermore, patients who 
Table 2 Correlations with total emergency department occupancy, ambulance diversion, and proportion of patients not seen within threshold waiting times

\begin{tabular}{|c|c|c|c|c|c|c|}
\hline \multirow[b]{2}{*}{ Variable } & \multicolumn{2}{|l|}{ ED occupancy } & \multicolumn{2}{|l|}{ Ambulance diversion } & \multicolumn{2}{|l|}{$\begin{array}{l}\text { Proportion of patients } \\
\text { not seen within TWT }\end{array}$} \\
\hline & $r(95 \% \mathrm{Cl})$ & $\mathbf{p}$ & $r(95 \% \mathrm{Cl})$ & $\mathbf{p}$ & r $(95 \% \mathrm{Cl})$ & $\mathbf{p}$ \\
\hline Access block ED occupancy & $0.96(0.91$ to 0.98$)$ & $<0.001$ & $0.75(0.49,0.88)$ & $<0.001$ & $0.83(0.65,0.93)$ & $<0.001$ \\
\hline Admissions & $0.60(0.26$ to 0.81$)$ & 0.002 & $0.30(-0.11,0.63)$ & 0.16 & $0.53(0.16,0.77)$ & 0.008 \\
\hline Discharges & $-0.10(-0.48$ to 0.31$)$ & 0.63 & $-0.34(-0.65,0.07)$ & 0.11 & $0.06(-0.35,0.45)$ & 0.79 \\
\hline LAP & $0.05(-0.36$ to 0.44$)$ & 0.93 & $0.19(-0.23,0.55)$ & 0.38 & $0.01(-0.39,0.41)$ & 0.98 \\
\hline Total attendances & $0.20(-0.22$ to 0.56$)$ & 0.36 & $-0.16(-0.53,0.26)$ & 0.45 & $0.46(0.07,0.73)$ & 0.02 \\
\hline Sea surface temperature & $-0.56(-0.79$ to 0.19$)$ & 0.01 & $-0.49(-0.75,-0.10)$ & 0.02 & $0.37(-0.04,0.67)$ & 0.08 \\
\hline
\end{tabular}

experience access block have a longer length of inpatient stay, thus exacerbating the problem, ${ }^{413}$ and this impairs access to emergency care.

A frequent response to this issue in the media is that it is the low acuity patients who are the cause of overcrowding. However, we have found that these "walk-in" patients do not cause overcrowding or ambulance diversion. This is also consistent with the international literature. ${ }^{8}$ One cubicle blocked by an admitted patient for 8 hours impairs the assessment of 24 low acuity patients (assuming 20 minute assessment times). Removing this admitted patient would improve patient flow within the ED. It is also noteworthy that we found a predictable seasonal increase in the admitted patient burden for hospitals, which should be considered in health planning policy.

It is interesting to note that compliance with waiting times was improving in 2001 against a stable background of access blocked patients, suggesting that EDs were striving to improve performance. However, in 2002 these efficiencies were lost because of the overwhelming effects of access block.

To improve ED performance and decrease ambulance diversion, steps need to be taken to improve patient flow and thereby reduce access block. Possible methods to achieve this include: ${ }^{14} 15$

- Increasing the availability of acute care beds

- Better home care, and urgent nursing home placement of the elderly

- Better organised and active discharge planning

- Speedier assessments in the ED, for example, improved turnaround times for laboratories, radiology, and consultants

- Speedier transfer to wards if admitted

- Better management of chronic disease in the community to avoid ED attendance

- Prevention of illness leading to ED attendance.

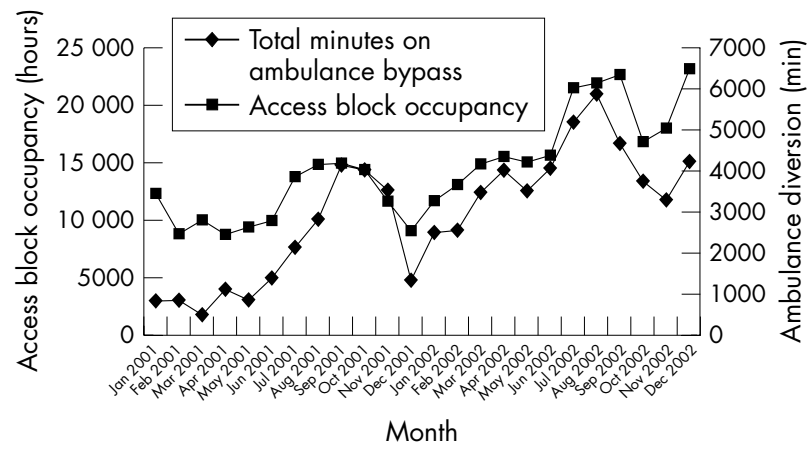

Figure 2 Relationship between access blocked patient occupancy and ambulance diversion.
Prevention strategies are frequently forgotten, such as fall prevention in the elderly. The elderly tend to be complex patients who are potentially long stay inpatients. Conversely, decreasing low acuity patient attendances will have minimal impact on decreasing ambulance diversion and ED overcrowding.

Other solutions include improvements to hospital flow of rehabilitation patients. For example, reducing the length of stay of one rehabilitation patient from 30 days to 15 days creates as many bed days as reducing the length of stay of 30 acute patients by half a day.

There are limitations to our study. We used data summed for whole months, whereas there is variability in the severity of ED overcrowding hour to hour. Other factors may have influenced ambulance diversion, such as the availability of staff in the ED; however, at least one study has shown this to be not significant. ${ }^{8}$ In addition, we have identified important overall trends, which could assist with strategies for a whole of system approach.

A second possible limitation is that the emergency physicians at each site used different criteria for ambulance diversion. It is possible that their approach may not have been consistent over the study period. However, the staffing was stable, and a large number of episodes of ambulance diversion were studied, hence, we believe that any effect of this was minimal.

Another limitation is that we did not include the impact of the outer metropolitan EDs. However, they represent only $18 \%$ of total ambulance presentations and have a different casemix to the major teaching hospitals we studied. In

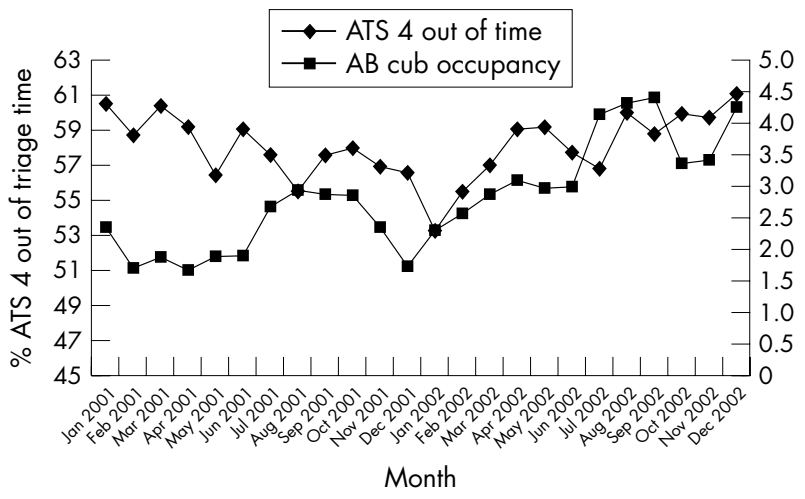

Figure 3 Correlation between access block cubicle occupancy and compliance with waiting time thresholds. ATS 4 patients comprise approximately $40 \%$ of total patient attendances. They are categorised as semi-urgent and should be seen by a doctor within 1 hour. Generally, they are ambulant and many are able to wait in waiting rooms. Their admission rate is $20-30 \%$ and their waiting times are greatly affected by lack of ED cubicle availability. Ab cub occupancy, access blocked cubicle occupancy. 
addition, this paper focuses on overcrowding, but other strategies may be useful to address waiting times.

In conclusion, we found that in Perth, reducing access block should be the highest priority in allocating resources to reduce ED overcrowding. This would result in reduced ambulance diversion and improved ED performance. Improving hospital inpatient flow is most likely to achieve this. These results are consistent with other studies.

\section{Authors' affiliations}

D M Fatovich, University of Western Australia, Australia Y Nagree, Armadale Health Service, Fremantle Hospital, Australia P Sprivulis, Acute Demand Management Unit, State Health Emergency Services, Department of Health, Western Australia, Australia

Competing interests: none declared

\section{REFERENCES}

1 Australasian College for Emergency Medicine. Standard terminology, 2001. www.acem.org.av/open/documents/triage.htm.

2 Fatovich DM. Emergency Medicine. BMJ 2002;324:958-62.

3 Richardson DB. Reducing patient time in the emergency department. Med J Aust 2003;179:516-17.

4 Liew D, Kennedy MP. Emergency department length of stay independently predicts excess inpatient length of stay. Med J Aust 2003;179:524-6.
5 Derlet RW, Richards JR. Overcrowding in the nation's emergency departments: complex causes and disturbing effects. Ann Emerg Med 2000;35:63-8.

6 Fatovich DM, Hirsch RL. Entry overload, emergency department overcrowding, and ambulance bypass. Emerg Med J 2003;20:406-49.

7 Thompson J. Coroners and lack of emergency department resources. J Emerg Med 1999; 17:541-2.

8 Schull MJ, Lazier K, Vermeulen M, et al. Emergency department contributors to ambulance diversion: a quantitative analysis. Ann Emerg Med 2003;41:467-76

9 Asplin BR. Does ambulance diversion matter? Ann Emerg Med 2003:41:477-80.

10 Trzeciak S, Rivers EP. Emergency department overcrowding in the United States. Emerg Med J 2003;20:402-5.

11 Schafermeyer RW, Asplin BR. Hospital and emergency department crowding in the United States. Emerg Med 2003;15:22-7.

12 Derlet RW. Overcrowding in emergency departments: increased demand and decreased capacity. Ann Emerg Med 2002;39:430-2.

13 Richardson DB. The access-block effect: relationship between delay to reaching an inpatient bed and inpatient length of stay. Med J Aust 2002; 177:492-5

14 Emergency Care Research Group at University of Warwick. Reducing attendance and waits in A\&E departments: A review and survey of present innovations. www2.warwick.ac.uk/fac/med/healthcom/emergencycare/ research/waits/

15 New Zealand Health Technology Assessment. Emergency department attendance. http://nzhta.chmeds.ac.nz/emergency.htm.

16 Sprivulis P. Estimation of the general practice workload of a metropolitan teaching hospital emergency department. Emerg Med 2003;15:32-7. 


\section{PostScript}

\section{LETTERS}

\section{A load of hot air}

Despite the widely held belief that air powered weapons are "toys" there are numerous reports in the popular press and medical literature that their use is associated with significant risk of injury. This is highlighted by the case of a 16 year old female who presented to the emergency department following being shot in the neck by an air powered rifle. She displayed no signs of upper airway obstruction and was haemodynamically stable but complained of increasing tightness around her neck. Examination revealed extensive surgical emphysema and a $5 \mathrm{~mm}$ entry wound overlying her cricoid cartilage that "whistled" on respiration; there was no exit wound. $x$ Ray revealed a metallic foreign body at the level of C6 in the prevertebral soft tissue.

Urgent ear, nose, and throat (ENT), and anaesthetic opinion were sought and the airway was secured following rapid sequence induction. The patient was then transferred to the intensive care unit (ITU). Panendoscopy on day 3 found the cords to be normal with granulation over the entry wound. The patient was extubated and discharged on day 5 with ENT follow up.

There may be as many as four million air powered weapons in the UK and there use is certain to impact on emergency health services ${ }^{1}$ - for example, the number of criminal offences involving air weapons is increasing from 7568 in 1995 to 10103 in 2000 , which accounted for $60 \%$ of all firearm offences in $2000 .^{2}$ There is a corresponding increase in number of associated injuries (1410 in $1995 v 1977$ in 2000) and in fact $20 \%$ of air weapon offences cause injury. ${ }^{3}$

Severity of injury depends on the site of the wound, shape of missile, degree of fragmentation, and the extent of cavitation. This in turn is proportional to surface area of impact, tissue density, and the velocity of the missile. Air powered weapons are capable of producing muzzle velocities of $900 \mathrm{ft} / \mathrm{sec}$, which is comparable to many hand guns. Wounding capability may be increased by the use of hunting pellets, "dieseling" (oiling the barrel to cause explosive propulsion of the missile), and "piggybacking" (firing two pellets together). Velocities required to penetrate tissues vary but are well within the limits of air powered weapons-for example, skin at $245 \mathrm{ft} / \mathrm{sec}$, bone at $350 \mathrm{ft} / \mathrm{sec}$, and ocular penetration at only $130 \mathrm{ft} / \mathrm{sec}^{4}{ }^{4}$ The risk of injury is well supported by numerous reports of ocular, cranial, vascular, thoracic, and abdominal injuries, some of which are associated with fatalities. Therefore air weapon injuries should be treated as low velocity gun shot wounds depending on the site of injury and any subsequent migration of the missile following appropriate resuscitation.

In light of recent high profile firearm incidents gun laws are set to tighten, including measures to limit the use of air weapons. Despite this it is important that health workers in the emergency setting are aware of the risks posed by the use of air powered weapons.
A Hudson

Anaesthetic Department, Princess of Wales Hospital, Bridgend, CF31 1RQ, UK; anthonyhudson@doctors.org.uk

\section{References}

1 Ceylan H, McGowan A, Stringer AD. Air weapon injuries: a serious and persistent problem. Arch Dis Child 2002;86:234-5.

2 Criminal Statistics England and Wales. 8th December 2000. http://www.archive.officialdocuments.co.uk/documents/cm50/5001-t33.htm (accessed 4 April 2005).

3 Criminal Statistics England and Wales. 8th December 2000. http://www.archive.officialdocuments.co.uk/documents/cm50/5001-\$37.htm (accessed 4 April 2005).

4 Bond SJ, Schnier GC, Miler FB. Air-powered guns: too much firepower to be a toy. J Trauma 1996;41:674-8.

\section{Unusual complication of an organophosphate poisoning}

A 50 year old female patient presented to the emergency room (ER) approximately $5 \mathrm{~h}$ after ingestion of an insecticide and showed signs of weakness, dyspnoea, sialorrhoea, and diaphoresis. Gastric lavage was carried out and activated charcoal administered as first aid measures.

Tachycardia, muscle weakness, fasciculations, and rales on auscultation of the chest were noted on examination. A serum cholinesterase of 161 units/L was also encountered. The mentioned symptoms disappeared after $6 \mathrm{mg}$ IV atropine plus $0.03 \mathrm{mg} / \mathrm{kg} \cdot \mathrm{h}^{-1}$ infusion, which was retired in a $12 \mathrm{~h}$ period. Pralidoxime was not available. Sertraline and clonazepam were prescribed by the psychiatrist. Relapse of cholinergic symptoms was observed on the second day following admission.

On day 4, tremor and cogwheel rigidity were observed followed by mask-like facies and a positive Babinski sign. On the day 6 after admission, neuromuscular respiratory failure developed and she was mechanically ventilated for 18 days (until day 24). As expected after prolonged ventilation, minor postural instability and dysarthria were observed following extubation, but no parkinsonian features were present. As her muscle weakness improved she was discharged on day 27. No agent to facilitate ventilation or any anti-parkinson drugs was needed.

An acute cholinergic phase followed by intermediate syndrome in organophosphate poisoning was diagnosed; ${ }^{1}$ however, tremors, dysarthria, cogwheel rigidity, and mask-like facies are unusual accompaniments following organophosphate intoxication.

These cardinal features of Parkinson's disease (TRAP-tremor, rigidity, akinesiabradykinesia, and postural instability) were described for the first time by Bhatt et al in 1999. ${ }^{2}$ However, Davis et al (1978) suggested that agricultural workers may be at risk for the late development of parkinsonism in a crop duster with numerous episodes of acute organophosphate intoxication and chronic organophosphate exposure. ${ }^{3}$

Bhatt et $a l^{2}$ described five patients who developed parkinsonism following different circumstances of exposure (one following ingestion of dimethoate, two following household fumigation, and two following entry into a previously fumigated environment) and suggested a dose dependent relation. The response to levodopa in these patients was poor. ${ }^{2}$

A 17 year old patient described by Shahar and Andraws (2001) developed extrapyramidal symptoms following treatment with atropine, toxogonin, and mechanical ventilation. She recovered completely following amantadine treatment. ${ }^{4}$

In the 81 year old woman described by Arima et al (2003), the diagnosis of parkinsonism was made on day 9 but the extrapyramidal manifestations were noticed on day $6 .^{5}$ This patient too suffered a severe acute cholinergic syndrome, which required treatment with large doses of atropine and 2pyridine aldoxime methiodidie. This patient responded well to biperidine ( $5 \mathrm{mg} /$ day) and recovery was complete in 8 days.

This case report reiterates the likelihood of symptoms and signs of parkinsonism developing following organophosphate poisoning. In our patient, the signs were noted following a severe acute cholinergic phase but prior to the development of the intermediate syndrome and recovery was complete when mechanical ventilation was stopped on day 24. It is necessary to observe patients for parkinsonian signs, particularly following recovery from a severe cholinergic phase.

A J Tafur, L Gonzalez, L A Idrovo, A Tafur Hospital Luis Vernaza, Guayaquil, Ecuador; alfonso_tafur@hotmail.com

\section{References}

1 Senanayake N, Karallede L. Neurotoxic effects of organophosphorus insecticides. An intermediate syndrome. NEJM 1987;316:761-3.

2 Bhatt MH, Elias MA, Mankodi AK. Acute and reversible parkinsonism due to organophosphate pesticide intoxication. Neurology 1999;52:1467-71

3 Davis KL, Yesavage JA, Berger PA. Single case study: possible organophosphate-induced parkinsonism. J Ner Ment Dis 1978;166:222-5.

4 Shahar E, Andraws J. Extrapyramidal parkinsonism complicating organophosphate insecticide poisoning. Eur J Paediatr Neurol 2001;5:261-4.

5 Arima H, Sobue K, So M, et al. Transient and reversible parkinsonism after acute organophosphate poisoning. J Toxicol Clin Toxicol 2003;41:67-70.

\section{Fit for the road?}

We read with interest the study by Frampton of emergency physicians' knowledge of DVLA guidelines.

Following a national questionnaire survey of lead clinicians in UK Accident and Emergency departments in $2003 \quad(41 \%$ return), we found results consistent with those in Frampton's study: correct driving advice was given in $97 \%$ post seizure, $75 \%$ post transient ischaemic attack (TIA), and $65 \%$ post unstable supraventricular tachycardia (SVT) in our study.

We also looked at musculoskeletal injury, for which no national guidance is available, ${ }^{2}$ and found there is little consistency in advice 
being given to patients with short lived $(<3$ months) musculoskeletal injuries on safe driving.

We would advocate the development of simple guidance on driving safely for patients with short term musculoskeletal injury:

- lower limb-ability to stand on injured limb and raise body with plantar flexion (braking/clutch/accelerator safety), and

- upper limb-ability to grip with equal force to the uninjured side and fully pronate and supinate the forearm (steering wheel safety).

We would also reinforce the importance of emergency department doctors being aware of the existing medical restrictions to driving.

M J Shepherd, A Wass

Consultant, Accident \& Emergency Dept, Pinderfield General Hospital, Wakefield matt.shepherd@midyorks.nhs.uk

P Gilligan

The Leeds General Infirmary, Accident \& Emergency 1 Far Moss, Alwoodley, Leeds, LSI7 7NU, UK

\section{References}

1 A Frampton. Who can drive home from the emergency department? A questionnaire based study of emergency physicians' knowledge of DVLA guidelines. Emerg Med J 2003;20:526-30.

2 DVLA. DVLA guidelines at a glance. http:// www.dvlagov.uk/at_a_glance (accessed 1 Dec 2003)

\section{BOOK REVIEW}

\section{Symptoms and signs of substance misuse}

M M Stark, J P-James. 2nd ed, 2003, £12.50, pp 64. ISBN 1-84110-106-0

This is a very handy booklet, intended to provide concise and readily accessible facts about symptoms and signs of commonly used drugs. As mentioned in the introduction, its targeted audience is not the experienced A\&E doctor or nurse, but healthcare professionals working in other environments, as well as public sector workers who often come into contact with persons under the influence of drugs. The booklet is also of particular use for partners, parents, or friends of people suspected of taking drugs.

The sections of the booklet are concise and helpful in establishing sequentially the various important aspects to consider in substance misuse. It starts with methods of administration and aspects of harm minimisation and risk reduction, and describes the various legal statutes and requirements. It gives an accurate table of the medical and health complications of substance misuse. One serious potential complication that can lead to death is not mentioned-that is, rhabdomyloysis, where an opiate user falls asleep after an overdose and remains unconscious in the same position, leading to muscle necrosis and potential death. The section on substance detection would be useful for enforcement agencies in monitoring drug profiles for potential prosecutions or healthcare professionals in monitoring detoxification programmes.

The booklet then goes on systematically to describe individual drug groups. The sections on management of some of the drugs are scant, but as mentioned above, this booklet is not targeted at medical doctors working daily in this field. The section on barbiturates does not cover the treatment of the acute intoxication.

The sections at the back of the booklet describing the Glasgow Coma Scale is helpful, but it would be more valuable if the authors had included the scores at which concern should be raised and the individual user is at risk.

C Perez Avila

\section{COURSE REVIEW}

\section{Medicine in remote areas}

Course run by ex+med UK Ltd; http://www.exmed.co.uk.

I enjoy my creature comforts at least as much as the next man (or woman). Why, then, had I ended up in the woods in the cold and dark, lugging someone on a stretcher (that we had to make ourselves) over ditches and between trees? Two reasons: firstly, I wondered if I might learn something on this course that would be useful if called out as part of a mobile medical team at a major incident, and secondly, I enjoy walking and felt I should have some preparation in case I came across someone injured on the hills.

Did I regret going? Only when I saw the state of the local nightclubs. I have previously been told that the single most important thing for effective teaching is to have credible teachers. On this criterion, the instructors on this course could not score any more highly. They have treated casualties in some of the most inhospitable environments there are; their knowledge is not derived from reading but has been gained the hard way. They are also good at teaching and at maintaining the balance between having fun and learning.

There is some didactic teaching (in specially refurbished accommodation) but I found the most useful sessions were the practical ones. Although I have previously (successfully) taken two different prehospital trauma courses, I learned a lot on this course. This was not just useful for work as part of a mobile medical team or for prehospital work; I learned things I have since used in the A\&E department (and when I have shown others, they really have said "wow!").

I would recommend this course to anyone working in A\&E provided they do not mind the cold or the rain too much. For people who have an interest in expedition medicine or in outdoors pursuits (and those who cannot find a good excuse for getting out of being part of a mobile medical team) this is a first rate course. If you go on this course I can confidently tell you that you will return with extra skills and knowledge and have fun acquiring them.

R Hardern

\section{CORRECTION}

doi: 10.1136/emj.2004.18002corr 1

In the paper titled Access block causes emergency department overcrowding and ambulance diversion in Perth, Western Australia (Emerg Med J 2005;22:351-354) an error has been spotted on page 353. In table 2 the $95 \%$ CI under ED occupancy, for sea surface temperature should read: -0.79 to -0.19. The journal apologises for this error. 